DOI: http://dx.doi.org/10.22201/iie.18703062e.1964.33.772

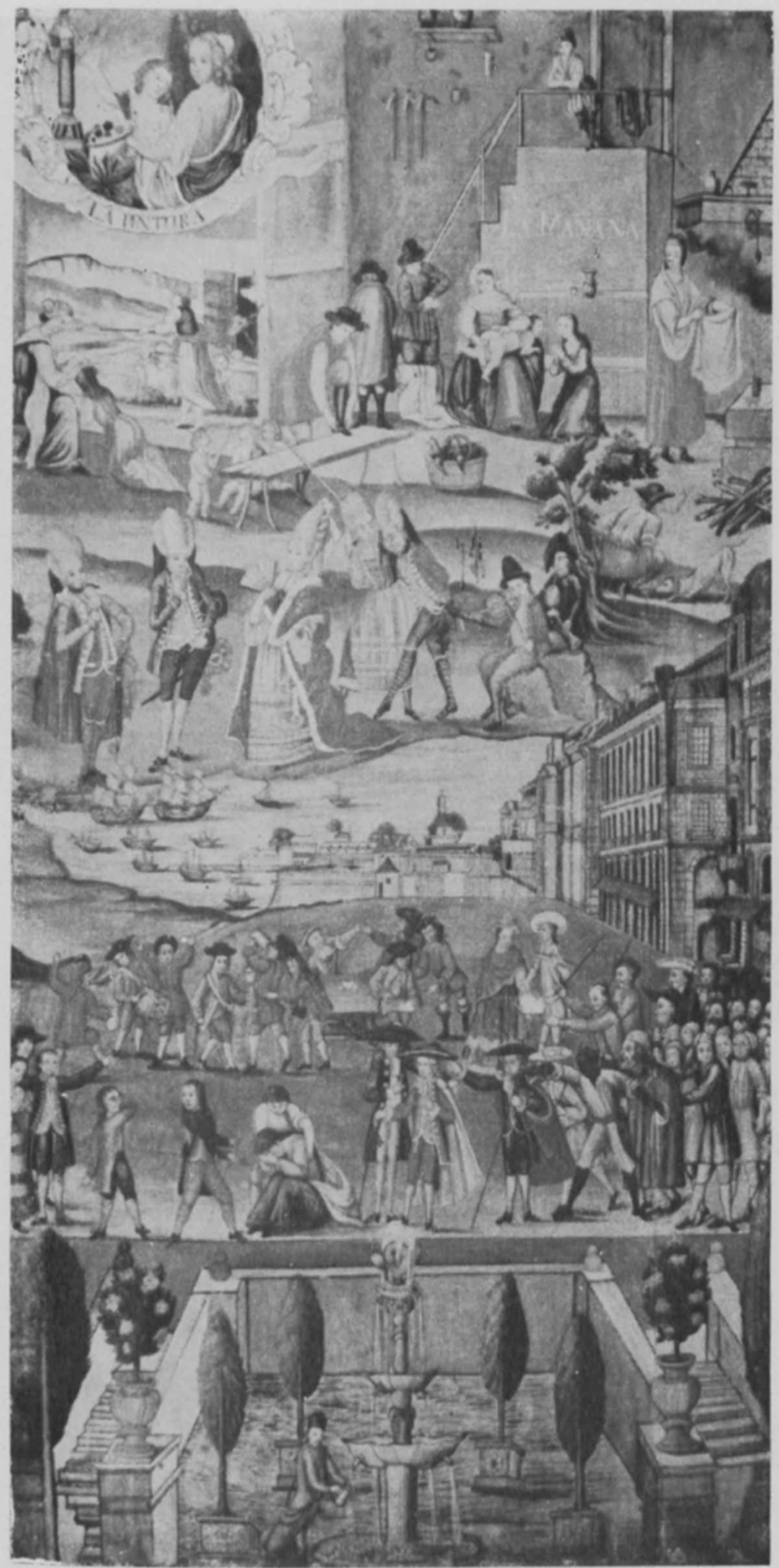

Panel alusivo a la pintura. Col. Eder. Cali, Colombia. 


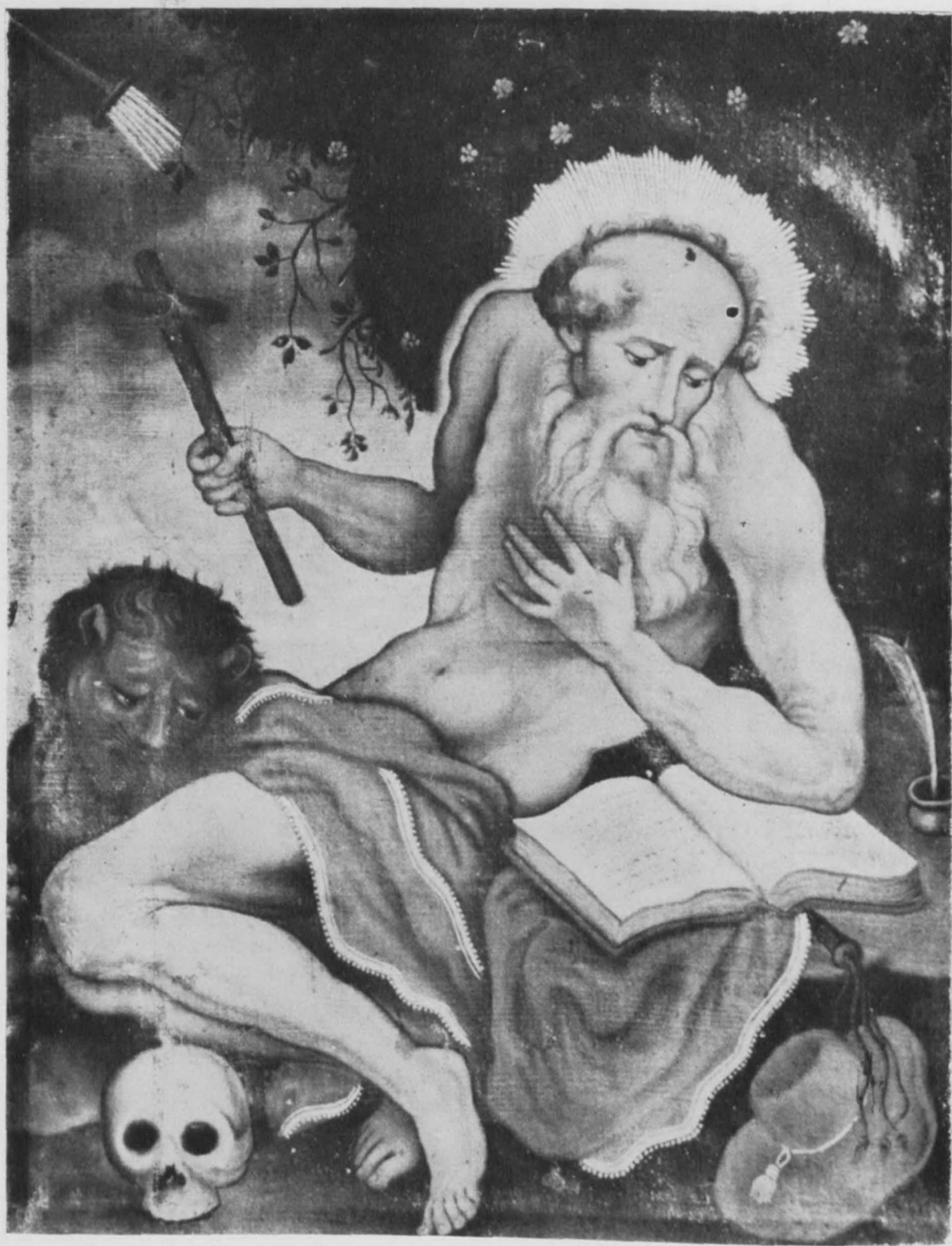

San Jerónimo. Col. Barona. Cali, Colombia. 


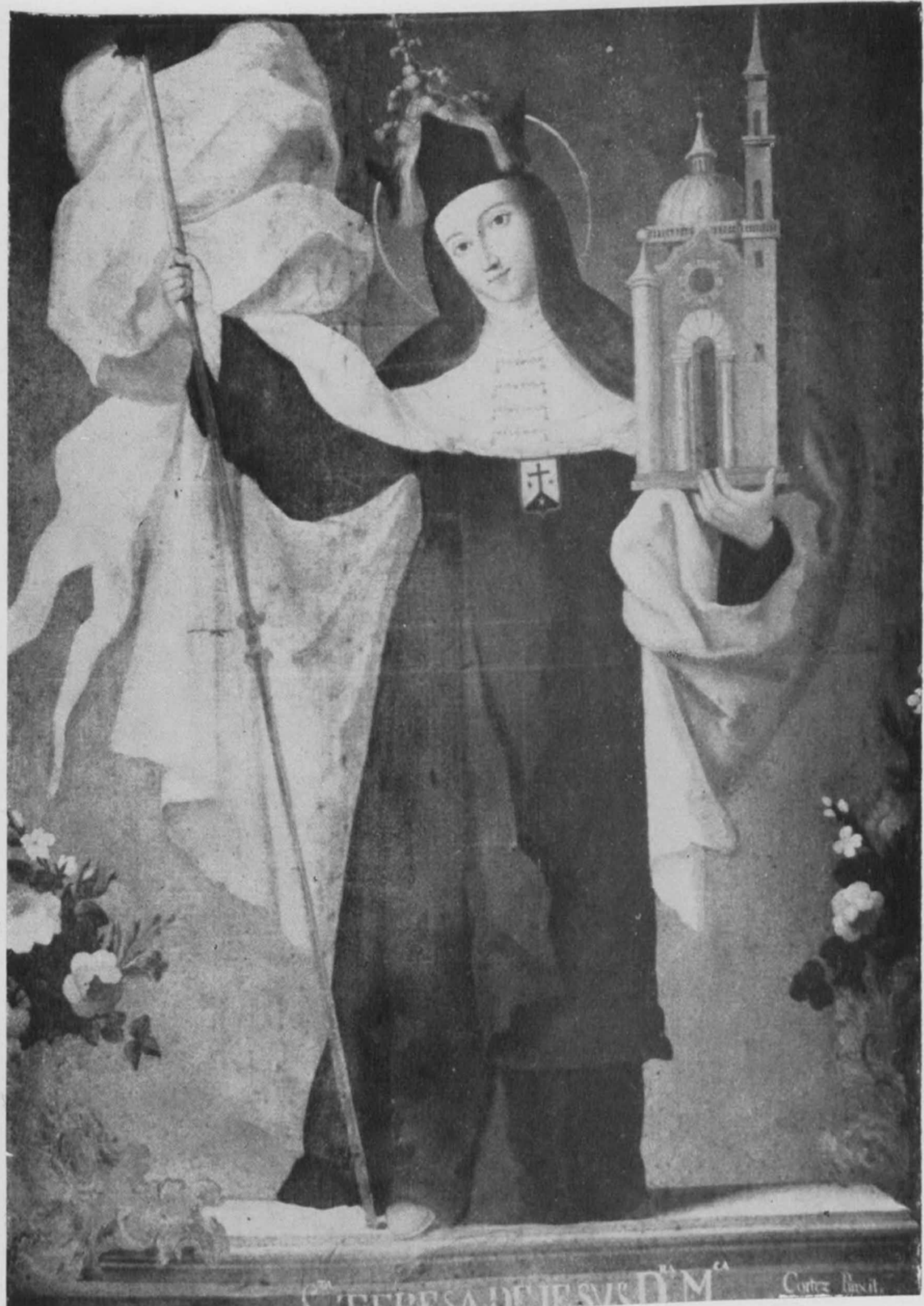

José Cortés. Santa Teresa de Jesús. Col. Jota Martínez. Cali, Colombia. 
DOI: http://dx.doi.org/10.22201/iie.18703062e.1964.33.772

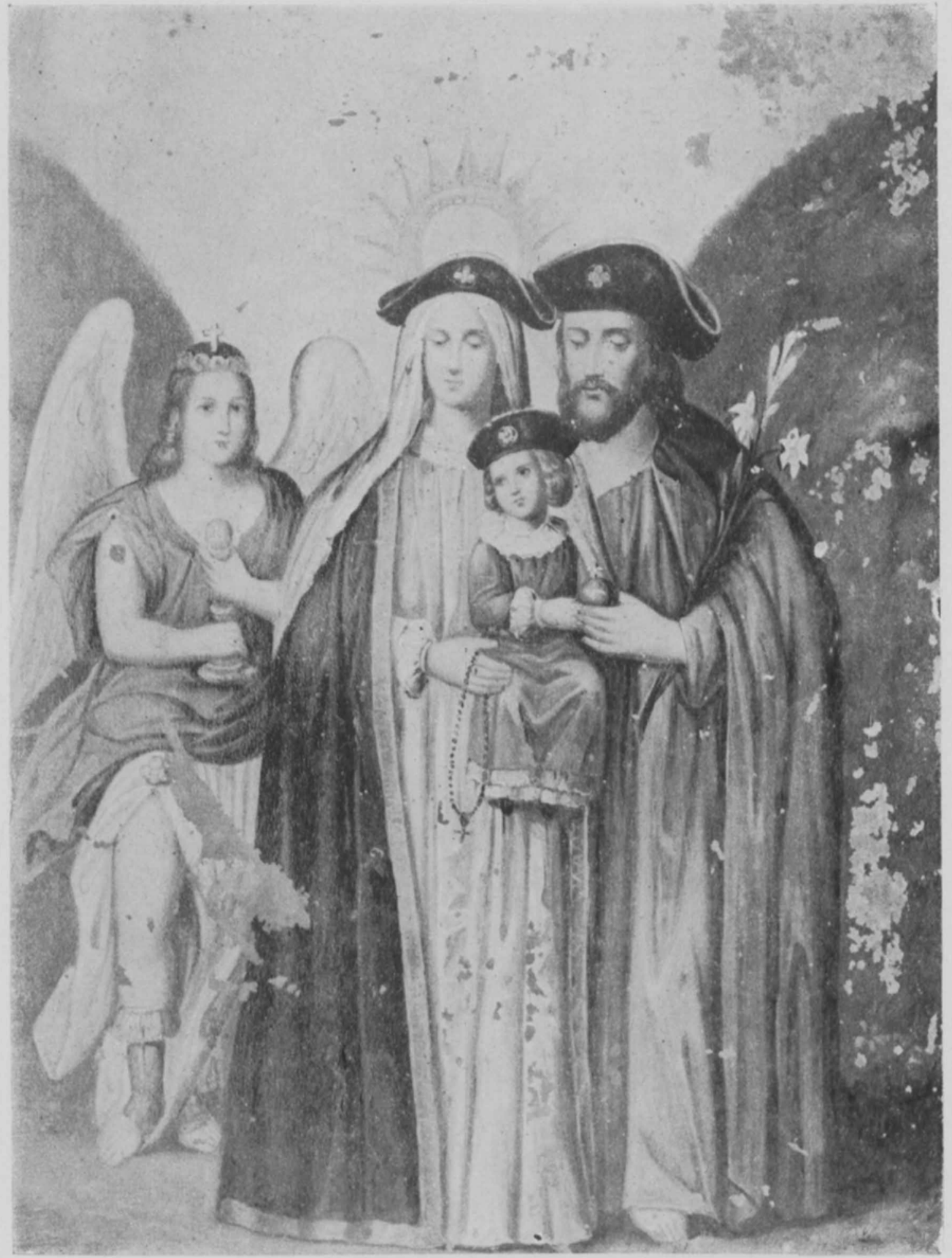

Virgen de la Peña. Col. Saavedra. Cali, Colombia. 


\section{PINTURAS DERIVADAS DE GRABADOS EN CALI}

Por Santiago Sebastian.

Paneles alusivos a la pintura y la Historia y la Matemática. Estos curiosos paneles de la colección Eder forman un biombo. Su autor debió de ser un artesano falto de técnica que cometió muchas torpezas en el dibujo, pero su interés radica en su complejidad, en su método narrativo, en su ingenuidad, en su ironía, etcétera. El panel de la Pintura tiene en la parte inferior una fuente de carácter arquitectónico, dibujada con errores de perspectiva. La escena del baile no puede ser más cómica como muestran las actitudes de los petimetres dieciochescos; es curiosa la forma de peluca, que desconozco existicra como moda, y más bien parece producto de esa exageración ridícula, tan patente en toda la composición. En contraste con los petimetres hay unos vcleros, en el puerto de una ciudad, cuya arquitectura parece francesa. La escena intermedia muestra la mezcla de motivos indianos y españoles, pero domina en ella ese aire de pintura de género, tan característico de lo flamenco.

El panel de la Historia y la Matemática presenta a estas alegorías en medallones de estilo rococó. Bajo la matemática hay una seric de construcciones de ambiente oriental, como puede apreciarse por los arcos de herradura. La escena inferior parece inspirada por la pintura galante francesa, presentando, a veces, como en el grupo central, ambiente de comedia. Aproximadamente en el centro se ve el perfil de una ciudad amurallada con numerosos campanarios cilíndricos, coronados por chapiteles cónicos. La escena siguiente parece ser un cjército realizando maniobras.

Para la composición de estos conjuntos superpuestos como estratos parece claro que su autor se sirvió de grabados o ilustraciones. El panel de la Pintura muestra en la parte superior una escena de género, muy flamenca, verdaderamente grotesca; con respecto a ella me ha sido posible constatar que procede de un grabado, ya que un cuadro de la escuela cuzqueña, en la iglesia parroquial de Calca (Perú), reproducido por Cossío del Pomar, ${ }^{1}$ presenta una escena igual a esta, donde además

1 Cossio del Pomar, Fclipe, Arte del Perí Colonial. México, 1958. Lam. 139. 
el copista puso al pie la frase que llevaba el grabado original, en la que se alude a los quehaceres del amanecer. Cossío tituló erróneamente el cuadro como Sagrada Familia. EI autor del panel de la colección Eder vio el sentido de la frase latina y por ello puso en el muro de la escalera la mañana. Podría fecharse a fines del siglo xvin.

Un grabado de Sadeler. En la colección Barona hay un San Gerónimo en posición de violento escorzo, está leyendo en un libro y con un crucifijo en una mano; casi no falta ninguno de sus atributos: la trompeta del Juicio Final, el león, la calavera, el capelo cardenalicio y el tintero con la pluma.

Es indudable que este lienzo deriva de un grabado de Sadeler, tomado de un cuadro de Jacopo Palma EI Viejo, aunque cambiando la colocación de los atributos. Que el grabado corrió por América está claro: en la catedral de Guatemala hay un altorrelieve con la misma escena. 2 La pintura caleña es un producto artesanal con algunos defectos y cierto arcaísmo por el uso de los dorados. Puede fecharse dentro de la centuria dieciochesca.

Un grabado del poblano José de Nava. En la colección Jota Martínez hay un lienzo de Santa Teresa con birrete doctoral, firmado por Cortés (Cortez Pinxit). Perteneció antes a la colección del Palacio Arzobispal de Popayán, donde hay una serie firmada por el mismo autor. Más ¿Quién fue Cortés? Creo que se trate del quiteño José Cortés y Alcocer, padre de una familia de pintores: Antonio, Nicolás y Francisco Javier. Se desconoce la procedencia de la serie payanesa, pero seguramente fueron adquiridos en Quito. Esto no se puede afirmar de una manera categórica ya que los hijos de Cortés vinieron a la Nueva Granada en el año de 1786 a participar en el equipo de pintores botánicos que dirigia Mutis, y precisamente se demoraron en Popayán, Antonio y Nicolás por enfermedad; posiblemente para esa fecha la serie ya se hallaba en la ciudad de Balcázar, pues el lienzo del Arcángel San Miguel lleva la fecha de 1771.

José de Nava fue el más fecundo y mejor grabador de Puebla, nacido en 1735 y muerto en 1817 . La mayor parte de su producción es religiosa.

I Berlin, H. Historia de la imagineria colonial en Guatemala. Guatemala, 1952. Figs. 6 y 7.

Kelemen, Pal. Baroque and rococo in Latin America. New York, 1951. I.áms. 58 a. y $190 \mathrm{~g}$. 
Este grabado copiado por Cortés, lo reproduce Romero de Terreros y cita: "La figura de la Santa es armónica y agradable y el movimiento de los paños apropiado; dentro de su sabor místico tiene un encanto singular." 3

Grabado de Ansclmo Garcia de Tejada. En la colección Saavedra hay un cobre con el tema de Nuestra Señora de la Peña, venerada en Bogotá, que es copia de un grabado de García de Tejada, fechado en 1818 y reproducido recientemente por Giraldo. $*$ Es interesante anotar que en fecha tan tardía los grabados ejercian aun influencia.

Universidad del Valle. Cali, Colombia.

3 Romero de Terreros, Manuel. Grabudos y Grabadores en la Nueca España. México, 1948. Laims. 278, pp. 510 y 512.

4 Giraldo, Jaramillo, Gabricl. El grabado en Colombia. Bogotá, 1960. Fig. 9. 